\title{
Influence of Mean Rooftop-Level Estimation Method on Sensible Heat Flux Retrieved from a Large-Aperture Scintillometer Over a City Centre
}

\author{
Mariusz Zieliński ${ }^{1}$ • Krzysztof Fortuniak ${ }^{2}$. \\ Włodzimierz Pawlak $^{2}$. Mariusz Siedlecki ${ }^{2}$
}

Received: 23 February 2016 / Accepted: 18 April 2017 / Published online: 4 May 2017

(C) The Author(s) 2017. This article is an open access publication

\begin{abstract}
The sensible heat flux $(H)$ is determined using large-aperture scintillometer (LAS) measurements over a city centre for eight different computation scenarios. The scenarios are based on different approaches of the mean rooftop-level $\left(z_{H}\right)$ estimation for the LAS path. Here, $z_{H}$ is determined separately for wind directions perpendicular (two zones) and parallel (one zone) to the optical beam to reflect the variation in topography and building height on both sides of the LAS path. Two methods of $z_{H}$ estimation are analyzed: (1) average building profiles; (2) weighted-average building height within a $250 \mathrm{~m}$ radius from points located every $50 \mathrm{~m}$ along the optical beam, or the centre of a certain zone (in the case of a wind direction perpendicular to the path). The sensible heat flux is computed separately using the friction velocity determined with the eddy-covariance method and the iterative procedure. The sensitivity of the sensible heat flux and the extent of the scintillometer source area to different computation scenarios are analyzed. Differences reaching up to $7 \%$ between heat fluxes computed with different scenarios were found. The mean rooftop-level estimation method has a smaller influence on the sensible heat flux ( -4 to $5 \%)$ than the area used for the $z_{H}$ computation ( -5 to $7 \%$ ). For the source-area extent, the discrepancies between respective scenarios reached a similar magnitude. The results demonstrate the value of the approach in which $z_{H}$ is estimated separately for wind directions parallel and perpendicular to the LAS optical beam.
\end{abstract}

Keywords Large-aperture scintillometer · Rooftop level · Sensible heat flux · Urban areas

Mariusz Zieliński

mrzielinski@up.krakow.pl

1 Department of Sustainable Development and Shaping of Geographic Environment, Pedagogical University of Cracow, Podchorążych St 2, 30-084 Cracow, Poland

2 Department of Meteorology and Climatology, Faculty of Geographical Sciences, University of Łódź, Narutowicza 88, 90-139 Łódź, Poland 


\section{Introduction}

In recent years, reliable large-area turbulent sensible and latent heat-flux estimates have become more desirable both for use in numerical models and remotely-sensed data analysis. Scintillometers provide highly reliable heat fluxes and have been successfully applied in turbulent sensible heat-flux measurements in many different environments ranging from natural (e.g., Green et al. 1994; De Bruin et al. 1995; Beyrich et al. 2002, 2012; Meijninger et al. 2002; Ezzachar et al. 2007; Evans et al. 2012) to urban areas (e.g., Kanda et al. 2002; Roth et al. 2006; Lagouarde et al. 2006; Pauscher 2010; Zieliński et al. 2013; Wood et al. 2013; Ward et al. 2014, 2015; Zhang and Zhang 2015). Large-aperture scintillometers (LAS) allow the estimation of the refractive index structure parameter $C_{n}^{2}$ along an optical path of up to several kilometres in length. Using auxiliary weather data, the temperature structure parameter $C_{T}^{2}$ and consequently the turbulent sensible heat flux, $H$ can be retrieved. Several authors investigated errors in the determination of the sensible heat flux related to uncertainties in the path-averaged friction velocity (Andreas 1992), the Bowen ratio (Solignac et al. 2009), or topography (Hartogensis et al. 2003; Lagouarde et al. 2006; Evans and De Bruin 2011; Gruber et al. 2014), or uncertainties in the scintillometer measurement itself (e.g., Hill 1988). However, there was no attempt to investigate the sensitivity of the sensible heat flux to the rooftop-level computation method.

For reliable estimation of the sensible heat flux, the precise height of the scintillometer beam is required. If the path is slanted or the beam height is varied, the effective measurement height $z_{\text {eff }}$ must be included in the computation of the sensible heat flux, since $C_{n}^{2}$ varies with height (Hartogensis et al. 2003; Evans and De Bruin 2011). When the scintillometer is deployed over natural areas or agricultural lands, the beam height can be measured accurately, since the topography along the optical path does not usually change significantly, and the height of obstacles does not differ to a significant degree. In urban areas, where the surface is covered with many artificial obstacles such as buildings and monuments, the determination of the measurement height is more complex, as the beam height varies along the optical path. Gruber et al. (2014) analyzed uncertainties in the sensible heat flux resulting from uncertainties in the topography beneath the optical path. They found that, in some cases, the heat flux was affected up to $20 \%$ by uncertainties in topography. Topography is more complex in urban than in natural or semi-natural areas (e.g., croplands), where most scintillometer studies have been performed. Thus, the detailed data on city structure, including the height of rooftops, are crucial for the reliable estimation of the sensible heat flux. Such data are provided by, e.g., the digital surface model, which is based on lidar measurements. However, there is still the question of how these data should be included in the beam-effective height computation, since different authors use different approaches (e.g., Lagouarde et al. 2006; Wood et al. 2013; Zieliński et al. 2013; Ward et al. 2014). Lagouarde et al. (2006) analyzed the sensitivity of the sensible heat flux to the aerodynamic roughness length $z_{0}$ and zero-plane displacement $z_{d}$, and found that the influence of $z_{0}$ is more pronounced than $z_{d}$ (a $\pm 0.5 \mathrm{~m}$ error in $z_{0}$ can lead to a $10 \%$ error in $H$ ). In addition, the reliable estimation of $z_{d}$ along the LAS path is crucial, as it strongly affects the effective height of the scintillometer beam.

We aim here to evaluate two methods of the mean rooftop-level derivation for the scintillometer path: (1) based on average building profiles along the optical path; (2) based on the weighted-average building height. Moreover, we present an approach that may reduce uncertainties in the heat flux resulting from different building heights on both sides of the optical path. In this approach, the mean building height is estimated separately for the wind direction perpendicular (two zones) and parallel (one zone) to the scintillometer path. For the 
heat-flux estimation, it is necessary to know the friction velocity $u_{*}$, which can be measured independently (e.g., with the eddy-covariance (EC) method) or retrieved from wind-speed profiles and the well-known Businger-Dyer relationship by an iterative procedure. We test to what extent the sensible heat flux computed with both algorithms (differing in the method of $u_{*}$ determination) is affected by the average building-height derivation method.

\section{Data and Methods}

\subsection{Scintillation Method: Sensible Heat-Flux Retrieval}

While we give here a brief description of sensible heat-flux retrieval from scintillometer measurements, more details on the scintillation method can be found in, e.g., Hill (1997), Meijninger (2003) and Moene et al. (2005). A large-aperture scintillometer provides the path-averaged refractive index structure parameter $\left(C_{n}^{2}\right)$, and together with auxiliary measurements of air temperature, humidity and atmospheric pressure, the temperature structure parameter $\left(C_{T}^{2}\right)$ can be calculated. Surface fluxes can then be related to $C_{T}^{2}$ via MoninObukhov similarity theory (e.g., Wyngaard et al. 1971),

$$
\frac{C_{T}^{2}\left(z_{m}-z_{d}\right)^{2 / 3}}{T_{*}^{2}}=f_{\mathrm{TT}}\left(\frac{z_{m}-z_{d}}{L}\right),
$$

where $z_{m}$ is the measurement height, $T_{*}$ is the scaling parameter for temperature, $f_{\mathrm{TT}}$ is a similarity function and $L$ is the Obukhov length defined as

$$
L=\frac{u_{*}^{2} T}{g \kappa T_{*}}
$$

where $g$ is the acceleration due to gravity (taken as $9.81 \mathrm{~m} \mathrm{~s}^{-2}$ ) and $\kappa$ is the von Kármán constant (0.40).

For LAS, the similarity functions given by Wyngaard et al. (1971) are the most commonly used, albeit with different constants (e.g., Andreas 1988; Hill et al. 1992; De Bruin et al. 1993). The friction velocity $u_{*}$ can be obtained from

$$
u_{*}=u\left(z_{m}\right) \kappa\left[\ln \left(\frac{z_{m}-z_{d}}{z_{0}}\right)-\Psi_{m}\left(\frac{z_{m}}{L}\right)+\Psi_{m}\left(\frac{z_{0}}{L}\right)\right]^{-1},
$$

where $u$ is the wind speed ( $\mathrm{m} \mathrm{s}^{-1}$ ) and $\Psi_{m}$ is the integrated Businger-Dyer stability function for momentum. As both $u_{*}$ and $T_{*}$ are connected via $L$, they must be found iteratively from Eqs. 1 to 3. Finally, the sensible heat flux $H$ can be computed from

$$
H=-\rho c_{p} u_{*} T_{*},
$$

where $\rho$ is the air density $\left(\mathrm{kg} \mathrm{m}^{-3}\right)$ and $c_{p}$ is the specific heat of moist air at constant pressure $\left(\mathrm{J} \mathrm{kg}^{-1} \mathrm{~K}^{-1}\right)$. The iterative procedure to determine $H$ can be simplified when $u_{*}$ is measured independently, e.g., with the EC method.

For computation of $H$ from scintillometer measurements, the effective height $\left(z_{\mathrm{eff}}\right)$ is used instead of $z_{m}-z_{d}$. The effective height of the scintillometer beam is introduced according to Hartogensis et al. (2003) for unstable conditions,

$$
z_{\mathrm{eff}}^{-2 / 3} f_{\mathrm{TT}}\left(\frac{z_{\mathrm{eff}}}{L_{\mathrm{OB}}}\right)=\int_{0}^{1}\left(z_{m}(x)-z_{d}(x)\right)^{-2 / 3} f_{\mathrm{TT}}\left(\frac{\left(z_{m}(x)-z_{d}(x)\right)}{L_{\mathrm{OB}}}\right) \mathrm{PWF}(x) \mathrm{d} x .
$$


where $z(x)$ is the beam height at distance $x$ from the transmitter, $z_{d}(x)$ is the displacement height at distance $x$ from the transmitter and $\operatorname{PWF}(x)$ is the scintillometer path-weighting function for $x$. An analytical approximation of $\operatorname{PWF}(x)$ was given by Evans and De Bruin (2011).

Kleissl et al (2008) found that for stable conditions, $z_{\text {eff }}$ reduces to the same relation as for near-neutral conditions,

$$
z_{\mathrm{eff}}=\left[\int_{0}^{1}\left(z_{m}(x)-z_{d}(x)\right)^{-2 / 3} \operatorname{PWF}(x) \mathrm{d} x\right]^{-3 / 2} .
$$

\subsection{Scintillometer Source-Area Estimation}

Several different footprint models for single point measurements have been introduced previously (e.g., Horst and Weil 1992; Schmid 1994, 1997; Hsieh et al. 2000). However, such footprint models cannot be used directly for LAS since, firstly, the scintillometer provides data averaged along a certain path; secondly, LAS is most sensitive to the turbulence close to centre of the optical path. Therefore, a combination of a single point footprint model and the scintillometer-path weighting function should be used, as shown by Meijninger (2003). To determine the LAS source area, we use a superposition of multiple model runs along the optical path, where the resulting footprints are multiplied by corresponding path-weighting function values and then summed,

$$
F\left(x^{\prime}, y^{\prime}, z_{\text {eff }}\right)=\sum_{i=1}^{N} f\left(x^{\prime}, y_{\prime}^{\prime}, z_{\text {eff }}\right) \operatorname{PWF}(x),
$$

where $F\left(x^{\prime}, y^{\prime}, z_{\text {eff }}\right)$ is the LAS footprint, $x^{\prime}$ is the downwind distance from the LAS path, $y^{\prime}$ is the crosswind distance from the centreline and $f\left(x^{\prime}, y^{\prime}, z_{\text {eff }}\right)$ is the flux footprint for a point located at $x$ distance from the transmitter.

In the present study, the analytical model of Schmid $(1994,1997)$ was used for footprint modelling, similar to the scintillometer source-area estimation used previously (Meijninger 2003; Göckede et al. 2005; Hoedjes et al. 2007; Timmermans et al. 2009; Samain et al. 2012; Ward et al. 2014, 2015).

\subsection{Measurement Site Description and Data Processing}

The scintillometer was deployed at Łódź, which is the third largest city in Poland (population 705,000 ), and is located about $120 \mathrm{~km}$ south-west of Warsaw. The city covers an area of $293 \mathrm{~km}^{2}$, of which nearly $145 \mathrm{~km}^{2}$ is a built-up area (buildings, streets, car parks etc.). The surface is slightly inclined from the north-east (278 m. a.s.1.) to the south-west (162 m. a.s.1.), though the relative height does not exceed $55 \mathrm{~m}$ in the city centre. There is a regular street pattern, as well as fairly uniform buildings mostly $15-20 \mathrm{~m}$ in height, and built between the end of the 19th and the beginning of the 20th century. The city centre is surrounded by residential districts dominated by 5-storey blocks of flats (approximately $15 \mathrm{~m}$ in height), with several of them reaching 10 floors. Several industrial areas are scattered throughout the city, of which many have been transformed into service and cultural areas. A few relatively small green parks are located in the city centre, while outside the centre, larger green areas are located. 


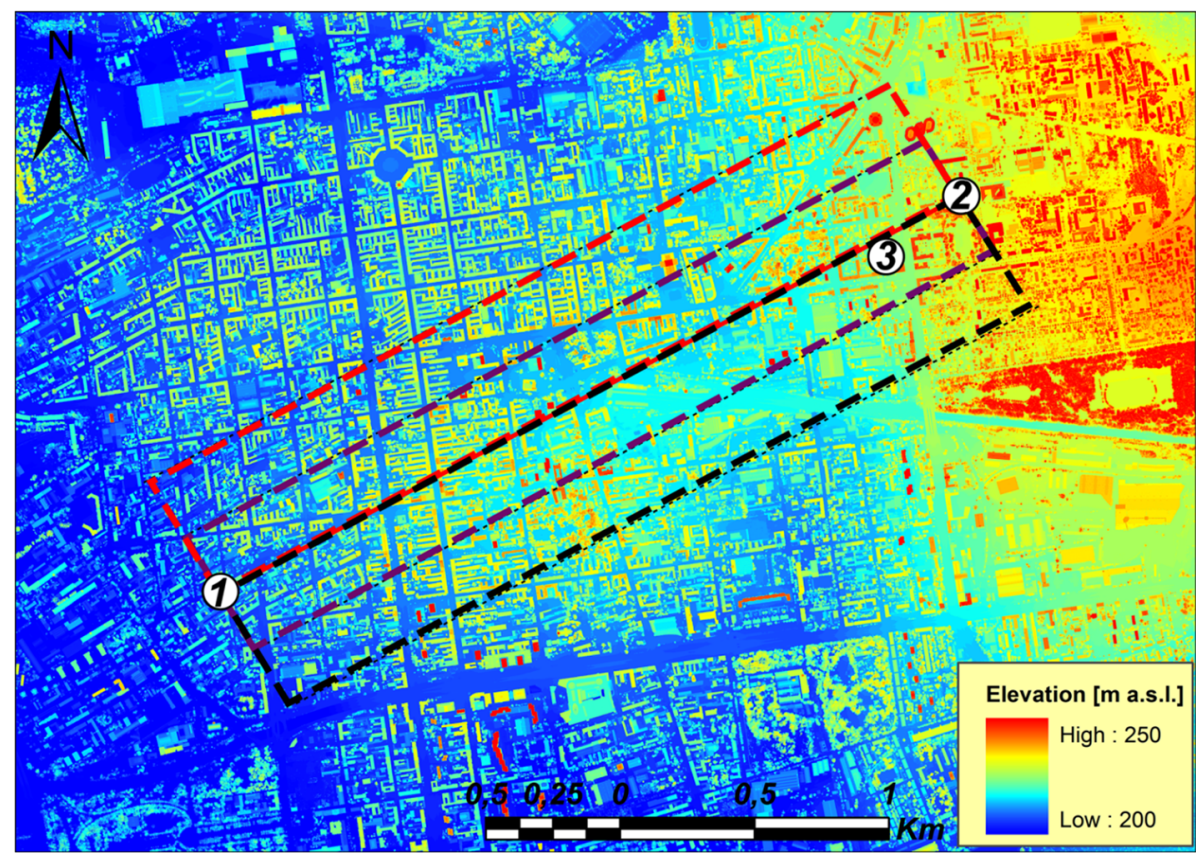

Fig. 1 Measurement sites in Łódź centre shown on a digital surface model map: 1 Lipowa site: LAS transmitter, EC system and radiation balance measurements (37 $\mathrm{m}$ above ground), 2 LAS receiver, 3 Narutowicza site: EC system and radiation balance measurements. Dashed lines indicate the area for which the effective measurement height was estimated (see text) for a wind direction approximately perpendicular ( $r e d$ for $260^{\circ}-045^{\circ}$ and black for $080^{\circ}-225^{\circ}$ direction) and parallel (purple for $045^{\circ}-080^{\circ}$ and $225^{\circ}-260^{\circ}$ direction) to the LAS path

The LAS measurements with a BLS900 infrared scintillometer (Scintec AG, Rottenburg, Germany) were conducted in the period 26 August 2009-26 November 2012, with the scintillometer transmitter mounted on a mast at a height of about $31 \mathrm{~m}$ above the ground. The mast itself stood on the roof of a 5-storey building located on the western side of the most densely built-up part of the city (Fig. 1). The LAS receiver was installed on the roof of a building $36 \mathrm{~m}$ tall, and located about $3.2 \mathrm{~km}$ north-east of the transmitter. The auxiliary data (heat fluxes from eddy covariance and weather data) were collected on the same mast on which the LAS transmitter was installed, and at an additional site located about $550 \mathrm{~m}$ south-west of the LAS receiver. More details concerning the measurement sites in Łódź can be found in Pawlak et al. (2011), Fortuniak et al. (2013) and Zieliński et al. (2013). Additionally, Sect. 3.1 provides more information on the surface characteristics and the LAS path height.

Scintillometer data were obtained at a frequency of $125 \mathrm{~Hz}$, and during the measurements, the saturation correction (Clifford et al. 1974) was applied in the calculation of $C_{n}^{2}$. For the computation of $C_{T}^{2}$ and consequently the sensible heat flux, auxiliary weather data (temperature, atmospheric pressure, humidity, wind speed and direction, Bowen ratio) from the EC tower at the Narutowicza site were used. A possible influence of the street canyon on the airflow around the EC tower at the Lipowa site was reported by Fortuniak et al. (2013). As a result, data from the tower were rejected unless data from the Narutowicza site were unavailable (data from the Lipowa site were used for $7 \%$ of cases). The sensible heat flux was computed in 1-h blocks with both the friction velocity from EC measurements, and from a separate iterative procedure. The flux direction was determined based on the heat flux 
obtained from the EC method, as other algorithms (e.g., Samain et al. 2012) had failed for our data. An analysis of the LAS and EC source areas revealed several similarities in the surface cover type depending on the wind direction. Therefore, for an inflow from $330^{\circ}-130^{\circ}$, the sign of the sensible heat flux from the Lipowa site was used to determine the direction of the heat flux measured by the LAS. For the remaining wind directions, the sensible heat flux determined at the Narutowicza site was used. In our computation, the similarity function proposed by Wyngaard et al. (1971), as modified by Andreas (1988) to reflect $\kappa=0.4$, was used.

\subsection{Mean Rooftop-Level Estimation Methods and Sensible Heat-Flux Retrieval Scenarios}

When LAS measurements are conducted over a surface covered with buildings of fairly uniform height, e.g., during the ESCOMPTE campaign in Marseille (Lagouarde et al. 2006), the mean rooftop level in the neighbourhood of the optical path may be enough to estimate the sensible heat flux reliably. However, if the topography and building height vary on both sides of the LAS path, the computation of $z_{H}$ from only the area located close to the path may result in uncertainties, especially for inflow from the direction approximately perpendicular to the LAS path (Fig. 2). In such conditions, the source-area size is about $4 \mathrm{~km}^{2}$ and only the area upwind to the LAS path contributes to the observed sensible heat flux. Thus, the surface topography of the downwind area barely affects the estimated values. On the other hand, when the wind direction is approximately parallel to the optical path, the source area extends to both sides. Moreover, it is twice as small (size $\approx 2 \mathrm{~km}^{2}$ ) than during inflow from the direction perpendicular to the path. It seems that for our measurements, it may not be enough to estimate $z_{H}$ based on the closest vicinity of the LAS path, as both the topography and the height of buildings differ significantly on its northern and southern sides. Instead of estimating $z_{H}$ from only one zone centred on the scintillometer beam path, we used three different zones for the wind direction approximately perpendicular and parallel to the path (Fig. 1). In studies from other cities (e.g., Lagouarde et al. 2006; Wood et al. 2013; Ward et al. 2014), $z_{H}$ was estimated in one zone centred on the LAS path of 100-200 m width. Our footprint modelling revealed that, for our dataset under unstable conditions, $50 \%$ of the sensible heat flux measured with LAS is always generated in the area extending up to $500 \mathrm{~m}$ from the LAS path for a wind direction perpendicular to the optical path (Table 1). Moreover, for $L>-100 \mathrm{~m}$, almost $80 \%$ of the heat flux is generated up to $0.5 \mathrm{~km}$ upwind of the LAS path (Fig. 2). For a wind direction parallel to the optical path, almost $90 \%$ of the sensible heat flux is generated within the $250 \mathrm{~m}$ distance from LAS path. Therefore, we decided to use zones of $500 \mathrm{~m}$ width for the estimation of $z_{H}$. The example single footprints for $L=-100 \mathrm{~m}$ and $u_{*}=0.75 \mathrm{~m} \mathrm{~s}^{-1}$, which is characteristic of unstable stratification at noon, are shown in Fig. 2.

For the determination of the mean rooftop level along the LAS path, we tested two slightly different approaches. The first method was based on the average building profiles, created on the basis of the digital surface model for each zone separately. Zones were divided into 100 sections located every $5 \mathrm{~m}$ from the LAS path. Along each line starting from the optical path and finishing at a line located $500 \mathrm{~m}$ from the path, the building profile was created. For the central zone, which is used for wind directions parallel to the optical path, profiles were prepared every $5 \mathrm{~m}$ up to $250 \mathrm{~m}$ in both directions. Next, all profiles were averaged to obtain one mean building profile for each zone. This method is referred to as the PRO method, and was also applied to obtain the average terrain elevation for each zone. 
Table 1 Maximal distance $(\mathrm{m})$ from the LAS path of the 50, 80 and $90 \%$ footprint isopleths for a defined Obukhov length $(L)$ and wind direction perpendicular to optical path

\begin{tabular}{lrrrr}
\hline$L(\mathrm{~m})$ & -500 & -100 & -50 & -25 \\
\hline Maximal distance of 50\% footprint isopleth from LAS path & 420 & 245 & 180 & 115 \\
Maximal distance of $80 \%$ footprint isopleth from LAS path & 975 & 485 & 330 & 215 \\
Maximal distance of $90 \%$ footprint isopleth from LAS path & 2030 & 950 & 610 & 385 \\
\hline
\end{tabular}

(a)

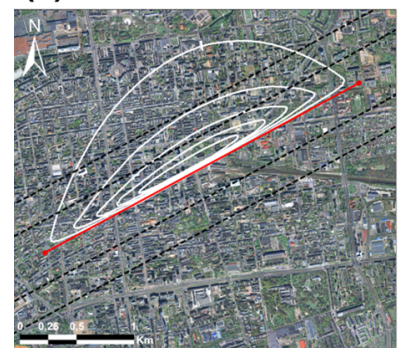

(b)

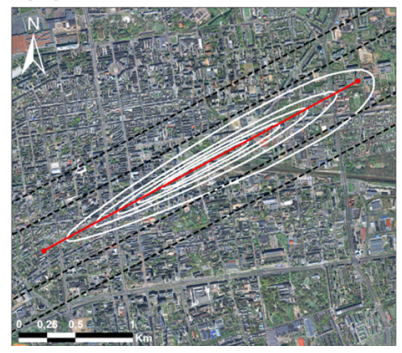

(c)

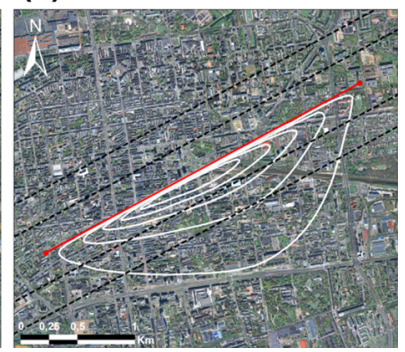

Fig. 2 Scintillometer source area at the 20,40,60, 80 and 95\% level under unstable conditions $(L=$ $-100 \mathrm{~m}, u_{*}=0.75 \mathrm{~m} \mathrm{~s}^{-1}$ ) for an inflow from $337.5^{\circ}(\mathbf{a}), 67.5^{\circ}(\mathbf{b})$, and $157.5^{\circ}(\mathbf{c})$. The scintillometer path is marked with a red solid line, black dashed lines were marked 250 and $500 \mathrm{~m}$ away from the optical path. Aerial photography source: maps.google.pl

In the second approach called the AVE method, the LAS path was treated as a number of single point measuring systems located along the path, with points separated by $50 \mathrm{~m}$ (overall 63 points). For each point, $z_{H}$ was computed as the average height of individual building weighted by its area. As with the PRO method, digital surface model data were used for the AVE method. To maintain a $500 \mathrm{~m}$ width of $z_{H}$ estimation zones, only buildings located within a $250 \mathrm{~m}$ radius from points located on the LAS path were used. While the LAS path for the central zone was in the middle, for the northern and southern zones, points were located on the lines lying $250 \mathrm{~m}$ to the north and south from the central path, respectively. For each zone, the $z_{H}$ profiles were interpolated on the basis of an average $z_{H}$ for the points located on the LAS path (central zone) or central line (northern and southern zone). This approach of $z_{H}$ estimation is similar to that usually applied to point measurements, e.g., EC method covariance.

Since the length of the LAS path in our case exceeded $3 \mathrm{~km}$, an additional correction for the Earth's curvature (Hartogensis et al. 2003) was used, amounting to $0.2 \mathrm{~m}$. We limited our investigation to unstable conditions and $H>10 \mathrm{~W} \mathrm{~m}^{-2}$ for two reasons: firstly, similarity functions for stable conditions are still under consideration (e.g., Andreas 1988; De Bruin et al. 1995; Hartogensis and De Bruin 2005); secondly, unstable conditions frequently occur in the city centre even during the night (e.g., Christen and Vogt 2004; Goldbach and Kuttler 2013; Kotthaus and Grimmond 2014a, b).

The sensible heat flux was computed separately for each of the two methods for the derivation of the mean building height (PRO and AVE), for two further scenarios, giving eight different combinations: (1) the mean building height estimated for one zone and three zones; (2) for algorithms including the friction velocity measured independently with the EC method and solved iteratively (IT method) with the well-known Businger-Dyer relationships. To distinguish different methods for the computation of the sensible heat flux, abbreviations based on the scheme presented in Fig. 3 are used hereafter. For example, PROIT3 stands 


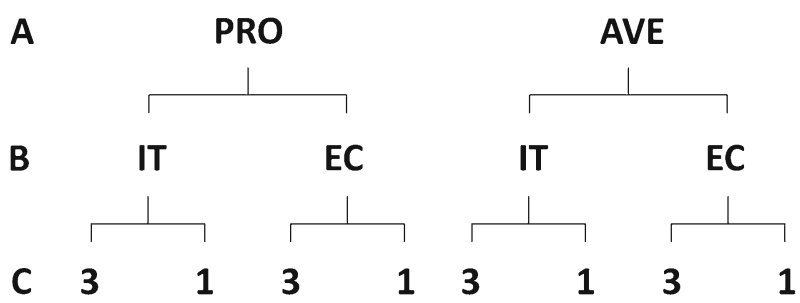

Fig. 3 Scheme of turbulent sensible heat-flux computation scenarios. Level A method of mean building height along the scintillometer path calculation (PRO average building profiles, AVE weighted average within a $250 \mathrm{~m}$ radius from points located on optical path), Level B friction velocity from iterative procedure (IT) or eddy covariance (EC), Level $\mathrm{C}$ number of zones used for mean building-height computation

for: (1) the mean building height along the LAS path computed as the average of building profiles; (2) the friction velocity computed iteratively; (3) the application of three zones for the computation of $z_{H}$. Note that in some cases, abbreviations are based on whether level $\mathrm{A}$ (e.g., PRO) or level B scenarios (e.g., PROEC) are used (see Fig. 3).

\section{Results and Discussion}

\subsection{Comparison of Two Methods of Average Rooftop-Level Determination}

The terrain and building profiles obtained using the AVE and PRO methods, separately for three zones, are shown in Fig. 4. While both methods yield relatively consistent results, the PRO method gives more detailed information than the profiles obtained with the AVE method, which are smoothed. The path height above the ground is not uniform between the transmitter and receiver. For the southern and central zones, this height ranges from approximately 30 to $40 \mathrm{~m}$, and for the northern zone, it is slightly higher, i.e., $31-41 \mathrm{~m}$. The beam passes at the lowest level above the city centre, where additionally its effective height is reduced by the presence of high buildings (Fig. 4). Closer to the receiver, buildings are lower than in the centre and the path elevation is larger, thus the effective height is the largest to the east. As a consequence, the scintillometer source area, especially its central part, is shifted towards the transmitter. In addition, in the eastern part, the source area extends further from the LAS path rather than closer to the transmitter.

Table 2 summarizes the average optical path height $z_{m}$ (computed according to Eq. 8) and the effective height $z_{\text {eff }}$ (computed with the iterative procedure). Surface parameters for both the PRO and AVE methods are given for each of the three zones separately. The estimation of averages of $z_{m}, z_{H}, z_{d}$ and $z_{0}$ along the optical path follows

$$
z_{Y}=\int_{0}^{1} z_{Y}(x) P W F(x) \mathrm{d} x,
$$

where the subscript $Y$ stands for $m$ in the case of the measurement height, $H$ for the building height, $d$ for the zero-plane displacement, and $z_{0}$ for the roughness length. The $z_{0}$ and $z_{d}$ values at each point along LAS path were estimated at $0.1 z_{H}$ and $0.7 z_{H}$ by a simple rule of thumb (Grimmond and Oke 1999).

The differences in $z_{m}$ between the zones reached $2.5 \mathrm{~m}$. The largest $z_{m}$ value was found for the northern zone $(36.3 \mathrm{~m})$, and the lowest for the southern zone $(33.8 \mathrm{~m})$, resulting from the relatively large differences between ground levels on both sides of the LAS path. 


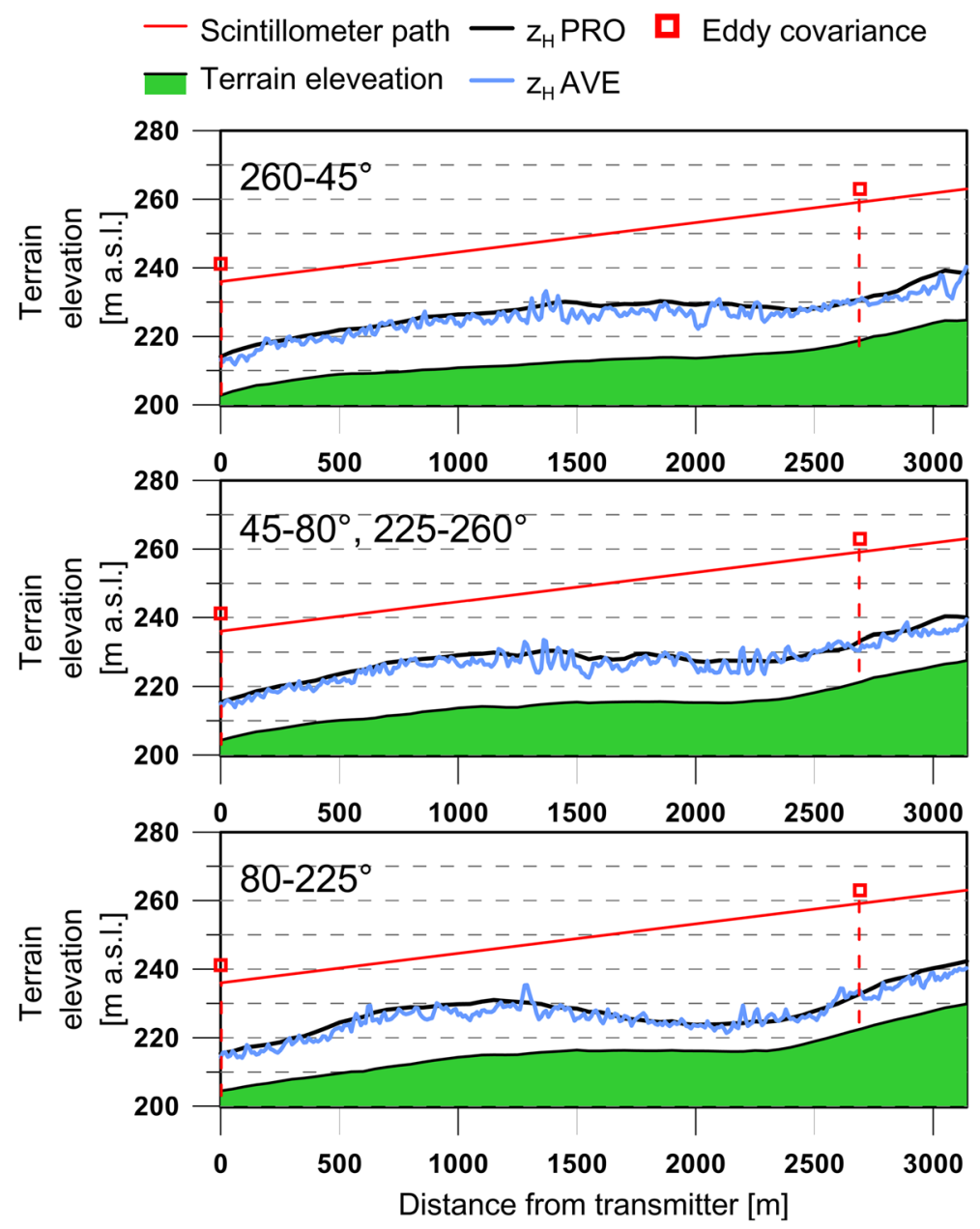

Fig. 4 Cross-section of terrain elevation (green)_average of specific zone, mean building height $z$ along the centre path for three zones (see Fig. 1). AVE weighted average, PRO profiles average

While a similar pattern was found for $z_{H}$, i.e., decreasing from the north to the south, the discrepancies between $z_{H}$ obtained for the individual zones were slightly higher $(2.7 \mathrm{~m}$ for the PRO method and $3.7 \mathrm{~m}$ for the AVE method) than in $z_{m}$. For each zone, $z_{H}$ computed with the AVE method was higher than $z_{H}$ estimated with the PRO method; the differences between the AVE- and PRO-derived building height varied from 0.9 to $1.9 \mathrm{~m}$. However, the discrepancies between $z_{\text {eff }}$ for the individual zones were not so distinct. In the northern zone, the PRO-derived $z_{\text {eff }}$ was $1.3 \mathrm{~m}$ larger than the AVE-derived $z_{\text {eff }}$, and for the central and southern zones, similar differences of 1.1 and $0.9 \mathrm{~m}$, respectively were found.

\subsection{The Influence of the Mean Rooftop-Level Determination Method on Sensible Heat Flux}

The friction velocity $u_{*}$ is essential for the processing of scintillometer data. In previously published results for urban areas, $u_{*}$ was estimated from wind-speed data using an iterative 


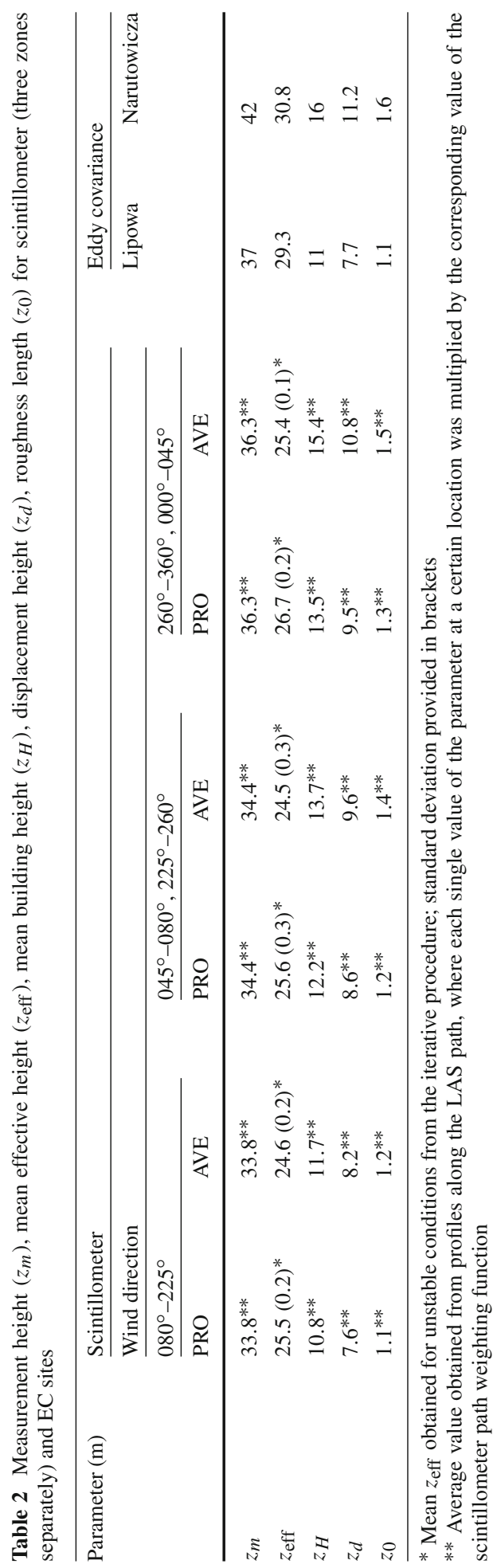



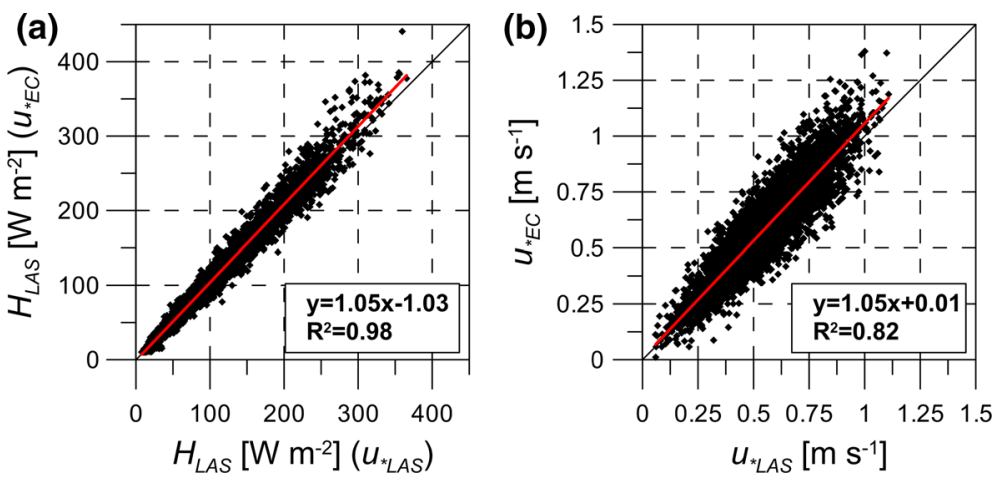

Fig. 5 Comparison of a turbulent sensible heat flux ( $H_{\text {LAS }}$ ) from a scintillometer obtained with the friction velocity $\left(u_{*}\right)$ from EC method $\left(u_{*} \mathrm{EC}\right)$ and iterative $\left(u_{*} \mathrm{LAS}\right)$ procedures for the AVEIT1 scenario, $\mathbf{b}$ friction velocity from EC $\left(u_{*} \mathrm{EC}\right)$ and $\mathrm{LAS}\left(u_{*} \mathrm{LAS}\right)$ for the AVEIT1 scenario

procedure (Lagouarde et al. 2006; Zieliński et al. 2013; Ward et al. 2014). However, the algorithm could be simplified by using $u_{*}$ measured independently with the EC method. Both $u_{*}$ measured independently and $u_{*}$ derived from an iterative procedure should be similar in magnitude when the wind speed is measured at the same height at which eddy covariance is performed, and when similar aerodynamic parameters in the source area of the LAS exist. However, a different turbulence intensity above the LAS and EC source areas may cause $u_{*}$ determined from the iterative procedure to diverge from $u_{*}$ obtained from EC measurements. Assuming that both $z_{0}$ and $z_{d}$ in the source area of the LAS are equal to those found in the EC source area, $u_{*}$ from an iterative procedure was found, on average, to be lower than values obtained with the EC method by $0.6 \%$, i.e., only $0.003 \mathrm{~m} \mathrm{~s}^{-1}$ (median). For approximately $50 \%$ of cases, the difference between both $u_{*}$ (from the iterative procedure and EC measurements) $<0.05 \mathrm{~m} \mathrm{~s}^{-1}$ (10\% difference) and for $15 \%$ of data, the difference $>0.15 \mathrm{~m} \mathrm{~s}^{-1}$. Taking into account $z_{0}$ and $z_{d}$ estimated on the basis of $z_{H}$ computed with the use of the AVE and PRO methods, $u_{*}$ from an iterative procedure was on average higher than the independently measured $u_{*}$ by $0.03 \mathrm{~m} \mathrm{~s}^{-1}$ and $0.05 \mathrm{~m} \mathrm{~s}^{-1}$, respectively. The largest difference between $u_{*}$ computed iteratively and with the EC method (AVE method: $0.43 \mathrm{~m} \mathrm{~s}^{-1}$, PRO method: $\left.0.42 \mathrm{~m} \mathrm{~s}^{-1}\right)$ was observed during strong winds $\left(7.5 \mathrm{~m} \mathrm{~s}^{-1}\right)$ on 5 October 2010 . However, high wind speeds were not always followed by a large divergence in $u_{*}$ from both algorithms. For example, on the previous day, the difference in $u_{*}$ estimated iteratively and from EC measurements only was $0.09 \mathrm{~m} \mathrm{~s}^{-1}$ despite a wind speed of $8 \mathrm{~m} \mathrm{~s}^{-1}$.

In general, $u_{*}$ from the EC method was higher than that obtained with the iterative procedure (Fig. 5). Similarly, the sensible heat flux computed with $u_{*}$ from the EC method differed from the iterative method by an average by $2.5 \%$. However, in extreme cases, the difference exceeded $20 \%$ (less than $6 \%$ of cases). For less than $1 \%$ of the cases and for a heat flux $<60 \mathrm{~W} \mathrm{~m}^{-2}$, differences exceeding $35 \%$ were observed. Such discrepancies show that it difficult to obtain a representative $u_{*}$ for the whole scintillometer source area from point measurements in urban areas. The LAS source area is frequently significantly larger than the source area of the EC measurement, covering a more diversified surface with aerodynamic parameters different than in the EC source area. Therefore, $u_{*}$ measured by an EC system mounted on a mast at some height might be representative of only the source area of that specific measurement system. Still, there is an open question to what extent the wind speed measured at a certain point is consistent with the conditions characteristic of the LAS source area. However, Ward et al. (2014) found a high correlation $\left(r^{2}=0.92\right)$ between the LAS 

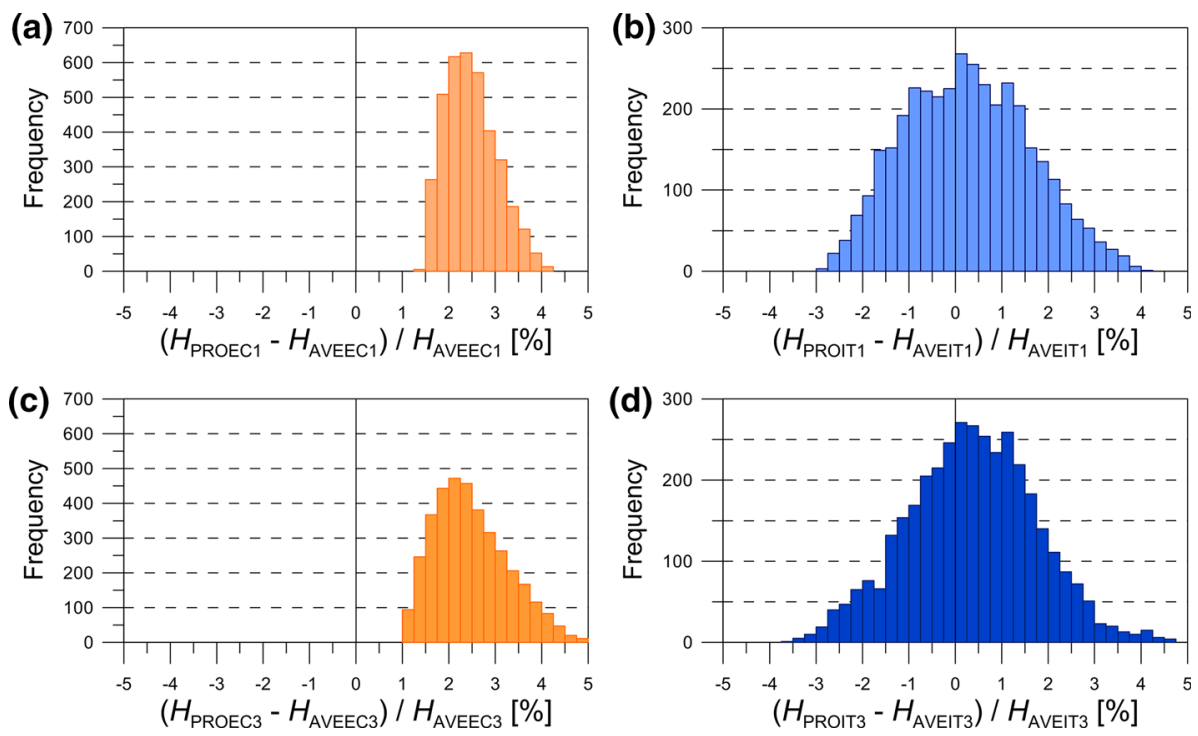

Fig. 6 Histograms of relative differences between the sensible heat flux $(H)$ computed with PRO and AVE methods of average rooftop-level estimation for one zone scenarios with the friction velocity from eddy covariance (EC) (a) and iterative (IT) (b) procedures and for three zones scenarios with the friction velocity from the EC method (c) and iteratively (IT) (d)

crosswind and an equivalent crosswind computed from the wind speed. It seems that, for urban areas, it is more appropriate to compute the heat flux with the full algorithm, including $u_{*}$ calculated from the wind speed and the wind profile corrected for stability and roughness length.

Nevertheless, we analyze herein the impact of the mean building-height-computation method on the sensible heat flux obtained from both algorithms that use $u_{*}$ calculated iteratively and with the EC method. In Fig. 6, the histograms of the relative difference between the sensible heat flux obtained with the PRO and AVE scenarios (see Fig. 3) are shown. When the heat flux is computed with the independently measured $u_{*}$, the discrepancies between the PROEC and AVEEC scenarios are unidirectional (Figs. 6a, c, 7a, c), i.e., the heat flux obtained for the PRO scenario (higher $z_{\text {eff }}$ ) is higher than the heat flux computed using the AVE scenario. When only one zone of $z_{H}$ computation is used, the PROEC1 scenario resulted in a higher heat flux than the AVEEC1 scenario by approximately 2-3\% (65\% of cases). For 20\% of the cases, discrepancies between the sensible heat flux using the PROEC1 and AVEEC1 scenarios are lower than $2 \%$, with a minimum at $1.5 \%$; for $15 \%$ of the cases, differences exceed $3 \%$ (maximum at $4.2 \%$ ). For $H>100 \mathrm{~W} \mathrm{~m}^{-2}$, differences $>2 \%$ are more frequent ( $85 \%$ of cases) than for $H<100 \mathrm{~W} \mathrm{~m}^{-2}$ (72\% of cases). The opposite situation is observed for differences $>3.5 \%$, which were twice as frequent ( $6 \%$ of cases) for $H<100 \mathrm{~W} \mathrm{~m}^{-2}$. The peak of the median diurnal difference between the PROEC1 and AVEEC1 scenarios is about $3 \mathrm{~W} \mathrm{~m}^{-2}$ and occurs around noon (Fig. 7a). The maximum difference reaches $10.4 \mathrm{~W} \mathrm{~m}^{-2}$. During the night, when the heat flux is relatively small, differences rarely exceed $1 \mathrm{~W} \mathrm{~m}^{-2}$. If three zones are used, the discrepancies $>3 \%$ are found for $25 \%$ of cases. For the northern zone, the difference between $z_{0}, z_{d}$ and $z_{\text {eff }}$ computed for the PRO and AVE methods are higher than in the central zone by zero, 0.3 and $0.2 \mathrm{~m}$, respectively. As a result, discrepancies between the heat flux derived with the PRO and AVE methods for the three zones scenarios 
(a)

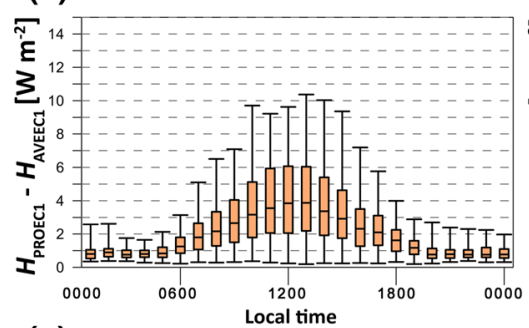

(c)

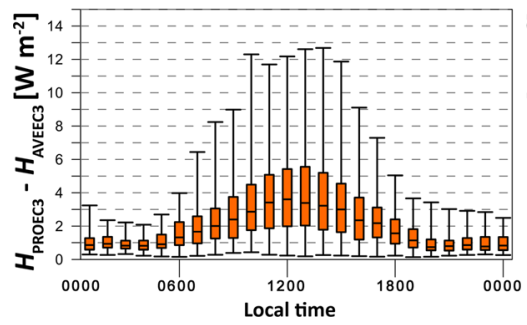

(b)

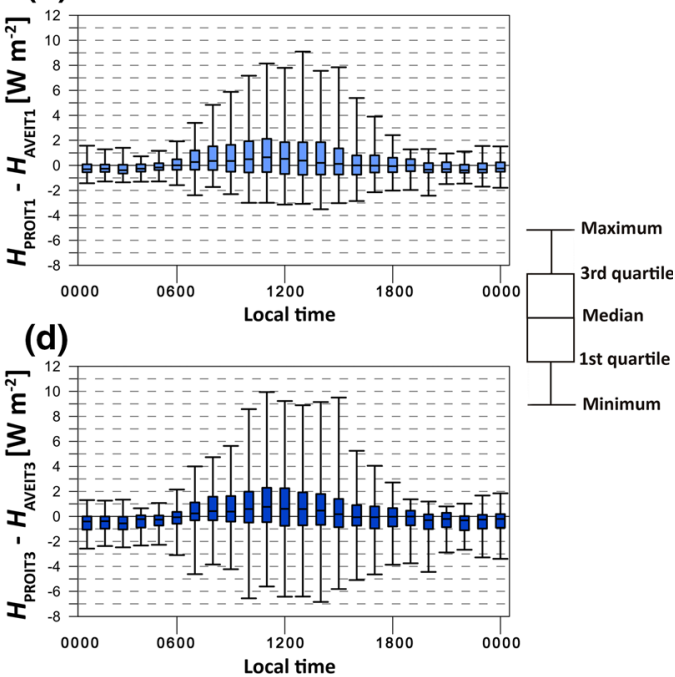

Fig. 7 Diurnal cycle of differences between the sensible heat flux $(H)$ computed with the PRO and AVE methods of average rooftop-level estimation for one zone scenarios with the friction velocity from the EC method (a) and iterative (b) procedures, and for three zones scenarios with friction velocity from the EC method (c), and iteratively (d). Note that only unstable conditions are shown here

reach up to $5 \%$. On the other hand, for the southern zone, the difference between PRO- and AVE-derived $z_{0}, z_{d}$ and $z_{\text {eff }}$ is lower by $0.1,0.4$ and $0.2 \mathrm{~m}$, respectively, than for the central zone. Therefore, small differences $(<2 \%)$ occur slightly more frequently $(10 \%$ increase in frequency). While the peak of the diurnal median difference is slightly lower and reaches $4 \mathrm{~W} \mathrm{~m}^{-2}$, the maximum differences reach $13 \mathrm{~W} \mathrm{~m}^{-2}$.

When taking into account the scenarios from the iterative group, the situation is slightly different. Generally, an increase in $z_{0}$ and $z_{d}$ results in an increase in the sensible heat flux, while for an increase in $z_{\text {eff }}$ the heat flux decreases. In the studied dataset, both $z_{0}$ and $z_{d}$ were estimated on the basis of only $z_{H}$ (determined separately using the PRO and AVE methods) with a simple "rule of thumb". As $z_{\text {eff }}$ depends on $z_{m}$ and $z_{d}, z_{H}$ obtained with the PRO method is lower than $z_{H}$ computed for the AVE method, and hence both $z_{0}$ and $z_{d}$ are lower for the PRO method as well. Since, the optical path height $\left(z_{m}\right)$ is constant for each zone and independent from the $z_{H}$ estimation method, a decrease or an increase of $z_{d}$ is followed by an increase or a decrease in $z_{\text {eff }}$, respectively. As a result, higher $z_{\text {eff }}$ values (increased heat flux) are followed by a lower $z_{0}$ and $z_{d}$ (decreased heat flux), and lower $z_{\text {eff }}$ values (decreased heat flux) are observed in relation to higher $z_{0}$ and $z_{d}$ (increased heat flux). Therefore, slight or negative differences between the sensible heat flux computed with the PROIT and AVEIT scenarios are frequently observed (Fig. 6). For the PROIT1 and AVEIT1 scenarios, the discrepancies range from -2.8 to $4.2 \%$, and in most cases (over $70 \%$ ), the absolute differences are smaller than $1.5 \%$. In $43 \%$ of the cases, the heat flux from the PROIT1 scenario is lower than that from the AVEIT1 scenario. The peak of the median diurnal difference is $0.5 \mathrm{~W} \mathrm{~m}^{-2}$ (Fig. 6b), which is a negligible difference, especially during spring or summer when the sensible heat flux at noon frequently exceeds $200 \mathrm{~W} \mathrm{~m}^{-2}$. On the other hand, for $25 \%$ of the cases from 1000 to 1400 local time, the difference between the heat flux obtained with the PROIT1 and AVEIT1 scenarios is $>2 \mathrm{~W} \mathrm{~m}^{-2}$, and reaches a maximum 

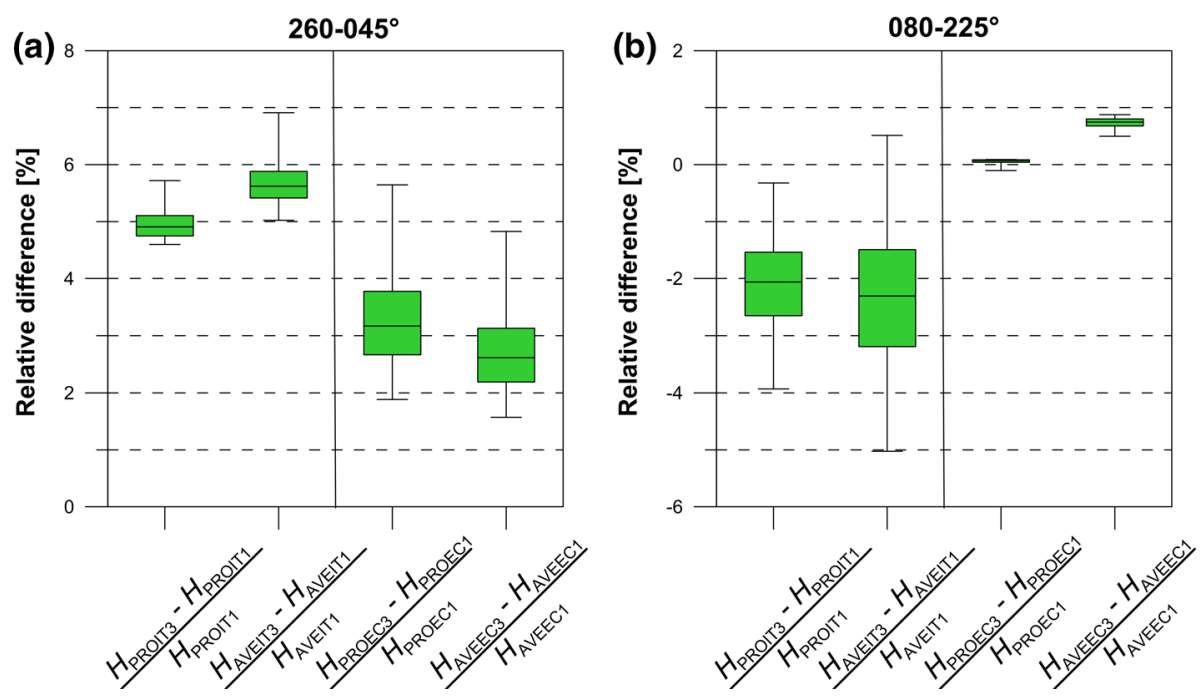

Fig. 8 Comparison between the turbulent sensible heat flux $(H)$ obtained with the building height estimated in one-zone and three-zone scenarios with the PRO and AVE methods for the northern (a) and southern (b) zones

of about $9 \mathrm{~W} \mathrm{~m}^{-2}$. The negative differences are most frequent during the night (negative median), but more frequent in the afternoon during the day. Likewise, when the PROTI3 and AVEIT3 scenarios are considered, a similar pattern in the differences is found. However, the cases exceeding $4 \%$ are slightly more frequent (about $0.7 \%$ ), and negative differences are less frequent (39\%), than for the one-zone scenarios (43\%). Here, a slight increase of the peak median diurnal difference to $0.8 \mathrm{~W} \mathrm{~m}^{-2}$, and only a $1 \mathrm{~W} \mathrm{~m}^{-2}$ increase, with up to a $10 \mathrm{~W} \mathrm{~m}^{-2}$ maximum difference, is observed (Fig. 7d). Most noticeable is the increase in negative differences. For the one-zone scenarios, negative differences reach $-3.5 \mathrm{~W} \mathrm{~m}^{-2}$, but for the three zones they exceed $-7 \mathrm{~W} \mathrm{~m}^{-2}$.

Relatively small discrepancies between the sensible heat obtained for the PROIT and AVEIT scenarios result from the fact that both $z_{0}$ and $z_{d}$ are estimated as a fraction of $z_{H}$, and the change of these parameters is followed by the change in $z_{\text {eff }}$. We suspect the difference may even rise if methods, other than a simple rule-of-thumb, in the derivation of $z_{0}$ are applied (e.g., Grimmond and Oke 1999), since $z_{0}$ has a greater effect on the sensible heat flux than does $z_{d}$ (Lagouarde et al. 2006). For our study, it appears that when the friction velocity is calculated iteratively, the method of $z_{H}$ estimation affects mostly individual situations. However, this effect would be less distinct in the long-term average diurnal cycle of the sensible heat flux, as both positive and negative difference between PRO and AVE methods are observed (Fig. 7b, d). Conversely, the method of $z_{H}$ estimation strongly affects the mean cycles of sensible heat flux whenever EC scenarios are applied.

As mentioned in the previous section, the main aim here is to present the strategy for $z_{H}$ estimation for scintillometer measurements over a complex and non-uniform urban surface. A comparison between the sensible heat flux computed for the data collected for wind directions approximately perpendicular to the LAS path for the three- and one-zone scenarios is shown in Fig. 8. For the northern and southern zones, 1843 and 1549 cases were analyzed (Fig. 8), respectively. The observed differences are more distinct for the scenarios based on $u_{*}$ obtained with the iterative method than the EC method. In the former case, the sensible heat flux is also 
affected by the differences in both $z_{0}$ and $z_{d}$ between the three-zone and one-zone scenarios of $z_{H}$ estimation. For the northern zone $\left(260^{\circ}-045^{\circ}\right)$, the application of three zones instead of one results in an increase of the sensible heat flux by approximately $5 \%$ and $6 \%$ for the PROIT and AVEIT scenarios, respectively. The maximum observed difference between the sensible heat flux computed for the AVEIT3 and AVEIT1 scenarios reachs $20 \mathrm{~W} \mathrm{~m}^{-2}$ at noon on 22 June 2010, while for the PRO scenarios, $18 \mathrm{~W} \mathrm{~m}^{-2}$ was detected at noon on 13 June 2010. Discrepancies $>10 \mathrm{~W} \mathrm{~m}^{-2}$ are observed for $18 \%$ and $22 \%$ of cases for PRO and AVE scenarios, respectively. Similarly, for the scenarios based on $u_{*}$ from the EC method, an increase in the sensible heat flux is observed; however, its magnitude is smaller $(2.5-3 \%$ on average). The maximum differences reach $5.7 \%$ for the PROEC and $4.9 \%$ for the AVEEC scenarios. While distinct discrepancies between $z_{0}$ and $z_{d}$ are observed for the southern and central zones, $z_{\text {eff }}$ values remain almost the same. As a result, the differences between the sensible heat flux computed for the EC scenarios ( $H$ is only affected by $\left.z_{\text {eff }}\right)$ are negligible, as they do not exceed $1 \%$. Due to large contrasts in the surface parameters for the southern and central zones, a strong divergence in the sensible heat flux computed for the iterative scenarios should be expected. However, as the $z_{\text {eff }}$ values in both zones are similar, the discrepancies in the sensible heat flux are small: $2 \%$ on average, and only for $25 \%$ of cases is this higher than $2.5 \%$. The sensible heat flux computed for the PROIT scenario with data from one zone is at most $8 \mathrm{~W} \mathrm{~m}^{-2}$ lower than the sensible heat flux obtained for the three-zone scenario. For the AVEIT scenario, the maximum differences reach $10 \mathrm{~W} \mathrm{~m}^{-2}$. Hence, the application of three zones for the estimation of $z_{H}$ provides a more reliable estimate of the sensible heat flux when the iterative algorithm is used.

\section{Influence of Mean Rooftop-Height Computation Method on the Scintillometer Footprint Estimation}

Different approaches to $z_{H}$ computation affect not only the magnitude of the sensible heat flux, but also the size of the scintillometer source area, i.e., the area contributing to the observed heat fluxes. To investigate the extent to which the $z_{H}$ estimation approach affects the size of the estimated scintillometer source area, two selected cases were analyzed for wind direction perpendicular to the LAS path: (1) with inflow from the northern sector i.e., $343.2^{\circ}$; (2) with inflow from the southern side of the LAS path i.e., $155.4^{\circ}$ ), and with similar weather conditions. For both cases, the footprint was computed for each of the eight scenarios.

For an inflow from direction $343.2^{\circ}$, the largest of the computed source areas, contributing $95 \%$ of observed heat flux (AVEIT3 scenario $-2.4 \mathrm{~km}^{2}$ ), is almost $38 \%$ greater than the smallest one (AVEEC3 scenario $-1.7 \mathrm{~km}^{2}$ ) (Table 3). In the second case, (inflow from $155.4^{\circ}$ ), the largest (PROEC3 scenario $-2.1 \mathrm{~km}^{2}$ ) and the smallest (AVEIT3 scenario $-1.7 \mathrm{~km}^{2}$ ) source areas differ by $24 \%$. When the scenarios from iterative or EC groups are considered separately, the discrepancies between the size of the source areas do not exceed $9 \%$. A comparison of the footprints modelled for the scenarios with one and three zones for the $z_{H}$ computation (Table 3; Fig. 9a-d) indicates that the source-area size is as sensitive to the area for which $z_{H}$ is determined as is the sensible heat flux. For instance, the difference in the sensible heat flux computed with AVEIT3 and AVEIT1 scenarios is $6 \%$ on average, and the size of source areas computed for both differs by approximately $4 \%$ and $8 \%$ under the inflow from the northern and southern sides of the LAS path, respectively (Fig. 9b). In addition to the differences in size, discrepancies in the shape of the footprint are observed as well. This is expected, since the application of three zones to the $z_{H}$ computation results in three different building and 
Table 3 Friction velocity $\left(u_{*}\right)$, Obukhov length $(L)$ and size of the scintillometer source area obtained for different scenarios for two cases with different inflow directions (dir)

\begin{tabular}{|c|c|c|c|c|c|c|}
\hline \multirow[t]{3}{*}{ Scenarios } & \multicolumn{3}{|c|}{18 June 20101200 UTC } & \multicolumn{3}{|c|}{2 June 20111200 UTC } \\
\hline & \multicolumn{3}{|c|}{$\operatorname{dir}=155.4^{\circ}, u=4.3 \mathrm{~m} \mathrm{~s}^{-1}, T_{a}=20.7^{\circ} \mathrm{C}$} & \multicolumn{3}{|c|}{$\operatorname{dir}=343.2^{\circ}, u=5.0 \mathrm{~m} \mathrm{~s}^{-1}, T_{a}=19.2^{\circ} \mathrm{C}$} \\
\hline & $u_{*}\left(\mathrm{~m} \mathrm{~s}^{-1}\right)$ & $L(\mathrm{~m})$ & Size $\left(\mathrm{km}^{-2}\right)$ & $u_{*}\left(\mathrm{~m} \mathrm{~s}^{-1}\right)$ & $L(\mathrm{~m})$ & Size $\left(\mathrm{km}^{-2}\right)$ \\
\hline PROIT3 & 0.64 & -73.50 & 1.81 & 0.74 & -123.51 & 2.36 \\
\hline PROIT1 & 0.66 & -79.78 & 1.79 & 0.72 & -120.13 & 2.29 \\
\hline AVEIT3 & 0.65 & -78.42 & 1.68 & 0.78 & -145.69 & 2.39 \\
\hline AVEIT1 & 0.68 & -89.64 & 1.82 & 0.75 & -134.65 & 2.29 \\
\hline PROEC3 & 0.71 & -96.76 & 2.08 & 0.63 & -82.08 & 1.81 \\
\hline PROEC1 & 0.71 & -96.82 & 2.03 & 0.63 & -85.26 & 1.83 \\
\hline AVEEC 3 & 0.71 & -98.75 & 1.93 & 0.63 & -84.98 & 1.73 \\
\hline AVEEC1 & 0.71 & -99.53 & 1.92 & 0.63 & -87.70 & 1.76 \\
\hline
\end{tabular}

In addition, the wind speed $(u)$ and air temperature $\left(T_{a}\right)$ are given. Note that for the EC scenarios, a fixed value of $u_{*}$ is used (from EC measurements)

elevation profiles. So the discrepancies, e.g., between the shape of the footprints obtained with PROIT3 and PROIT1 scenarios (Fig. 9a), reflect the differences between the building and terrain profiles for the northern, southern and central zones.

In Fig. 9e, the footprints obtained for the PRO and AVE methods are shown; it seems that for the northern zone, both methods indirectly yield footprints very similar in size $(1 \%$ difference) and shape. Since more detailed profiles can be obtained using the PRO method, the resulting source area isopleths are more irregular than those obtained using the AVE method. With the iterative method, both $z_{0}$ and $z_{d}$ are estimated based on $z_{H}$, and a similar effect to that mentioned for the heat flux is observed, i.e., increased values of aerodynamic parameters are associated with lower $z_{\text {eff }}$, and vice versa. As a consequence, the differences between $z_{0}, z_{d}$ and $z_{\text {eff }}$ for the PRO and AVE methods are blurred to some extent. In the southern zone, $z_{0}$ and $z_{d}$ determined with both PRO and AVE methods are similar in magnitude, and as a result for that zone, $z_{\text {eff }}$ values have a greater influence on the source-area size. For the inflow from the southern side of the LAS path, the footprint modelled for the PROIT3 scenario is approximately $8 \%$ larger than that computed for the AVEIT3 scenario. The discrepancies between the footprint computed for the PROEC3 and AVEEC3 scenarios reach 5\% on 2 June 2011 and $8 \%$ on 18 June 2010 (Table 3). In contrast to the iterative method, in the scenarios including $u_{*}$ determined from the EC method, the size of the footprint for the PROEC3 scenario is always larger than that modelled for the AVEEC3 scenario.

The largest contrast is observed between the footprints computed for the PROEC and PROIT scenarios, as well as for the AVEEC and AVEIT scenarios. For instance, when $u_{*}$ from the iterative procedure is similar in magnitude to $u_{*}$ from the EC measurements (Table 3 ), the size of the source area obtained for PROEC3 and PROIT3 scenarios is similar (Fig. 9f). However, when $u_{*}$ from EC is almost $0.1 \mathrm{~m} \mathrm{~s}^{-1}$ larger than $u_{*}$ obtained with iterative method, the size of the source area for both scenarios differs significantly. This indicates that EC scenarios should preferably be used if the aerodynamic parameters in the source area of the eddy covariance are similar to those observed in the LAS source area. The friction velocity determined from the iterative procedure is often more representative of the heat-flux source area and thus, iterative scenarios are more suitable for heterogeneous urban areas. 
(a)

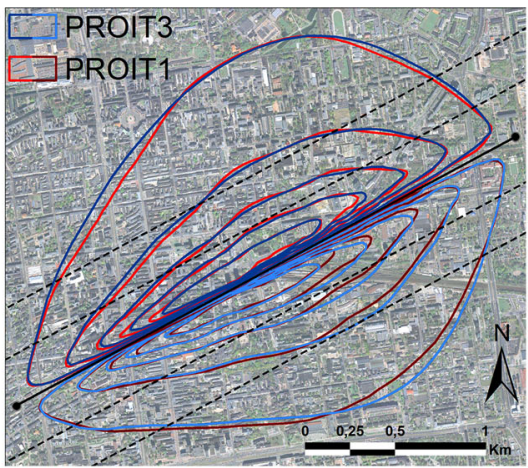

(c)

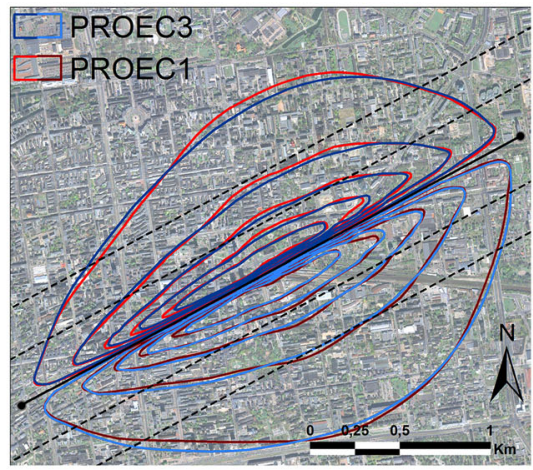

(e)

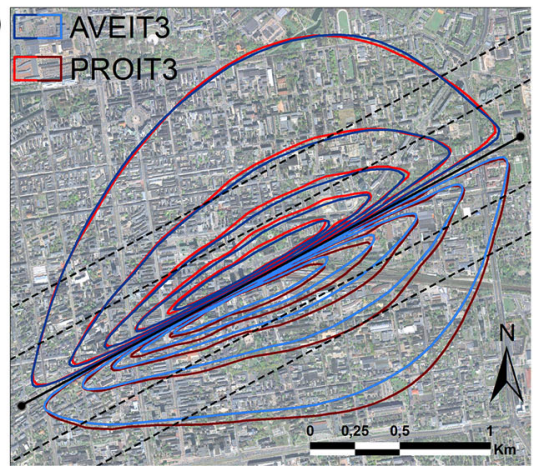

(b)

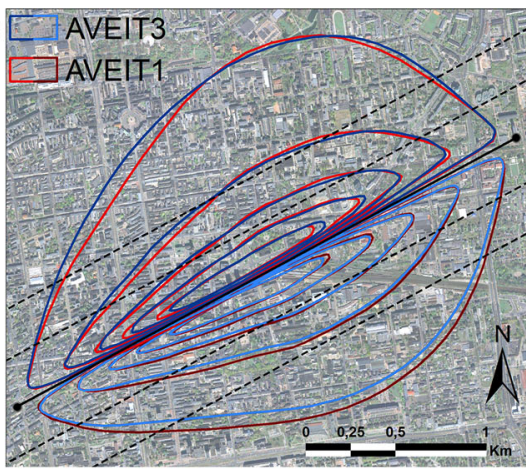

(d)

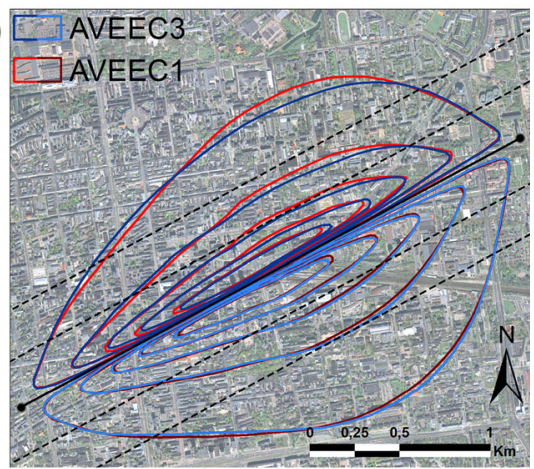

(f)

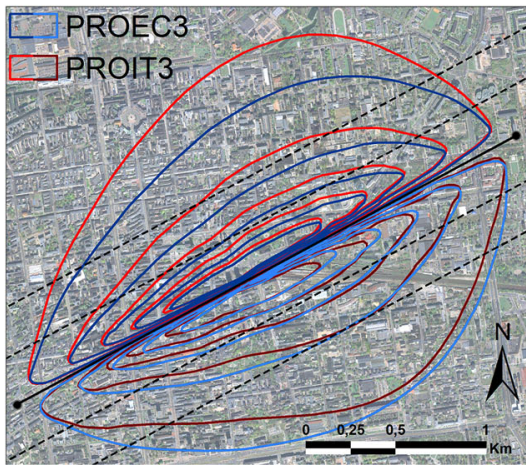

Fig. 9 Comparison of scintillometer source areas estimated for selected scenarios of the sensible heat-flux computation in two cases under unstable conditions and with wind directions approximately perpendicular to the scintillometer path: (1) 2 June 20111200 UTC (inflow from 343.2 ${ }^{\circ}$ ); (2) 18 June 20101200 UTC (inflow from $155.4^{\circ}$ ). Footprints indicate contributions of 20, 40, 60, 80 and $95 \%$ of the observed heat flux. The scintillometer path is marked with a black solid line, black dashed lines are marked 250 and $500 \mathrm{~m}$ away from the optical path. Aerial photography source: maps.google.pl

\section{Summary and Conclusions}

We analyzed eight different scenarios of sensible heat-flux computation that could be used in urban areas. While the presented scenarios do not represent all available options of heat-flux retrieval, they provide an insight into several uncertainties in the sensible heat flux related 
to the different methods of computation of average rooftop level along the scintillometer path.

The sensible heat flux computed fully iteratively $\left(u_{*}\right.$ solved iteratively) and the simplified algorithm $\left(u_{*}\right.$ measured independently using the EC method) should converge when the aerodynamic parameters for the scintillometer and eddy covariance source areas, and turbulence intensities are similar. Such conditions, however, may not be found in heterogeneous urban areas. We found, that when $u_{*}$ from the iterative procedure is computed with $z_{0}$ and $z_{d}$ equal to that in the EC source area, $u_{*}$ differs by $0.6 \%$ on average than that obtained with the EC method. However, for $15 \%$ of the cases, the discrepancies exceed $0.15 \mathrm{~m} \mathrm{~s}^{-1}$. When different surface parameters, computed with the PRO and AVE methods were used, the average difference increased to approximately $2.5-3.5 \%$ depending on the $z_{H}$ estimation method, and the maximum observed difference between $u_{*}$ from the EC method and $u_{*}$ from iterative procedure exceeded $0.4 \mathrm{~m} \mathrm{~s}^{-1}$. If aerodynamic parameters observed in the eddy-covariance source area significantly diverge from parameters characteristic of the scintillometer source area, we recommend applying the full iterative procedure, which includes the calculation of $u_{*}$.

Two different approaches of the mean rooftop-level estimation along the scintillometer path are applied herein: (1) average profiles of terrain and building elevation (PRO method); (2) weighted-average building height within a 250-m radius from points located on the optical path (AVE method). Both methods result in slightly different values of $z_{H}$ and, consequently, other parameters $\left(z_{0}, z_{d}\right)$. Therefore, the sensible heat flux computed with the PRO and AVE methods differs to some extent. In general, the discrepancies between a heat flux derived using the PRO method and the AVE-derived heat flux do not exceed 5\%. For the algorithms based on $u_{*}$ from EC measurements, the PRO method always yields a sensible heat flux greater than the AVE method by about 2-3\%. On the other hand, the iterative method produced differences in the sensible heat flux computed with the PRO and AVE methods that range from -4 to $5 \%$. This results from the fact that when $z_{0}$ and $z_{d}$ are estimated on the basis of $z_{H}$, the effects of a higher $z_{0}$ on the sensible heat flux are diminished by a lower $z_{\text {eff }}$. Had $z_{0}$ been determined from the aerodynamic approach (e.g., Grimmond and Oke 1999), the discrepancies between the sensible heat fluxes computed with the PRO and AVE methods might have been different. Moreover, in the iterative scenarios, the method for $z_{H}$ determination appears to play a more important role in the specific cases of the sensible heat flux rather than for the long-term average values.

A new approach is shown for $z_{H}$ estimation with scintillometer measurements conducted over a heterogeneous urban surface with varying building heights and terrain elevation. Instead of calculating the mean rooftop level in one zone centred on the optical path, we recommend using three zones separately for the wind direction perpendicular (two zones) and parallel (one zone) to the LAS path. The $500 \mathrm{~m}$ width of zones was based on the footprint modelling, as much of the time under unstable conditions $80-90 \%$ of the sensible heat flux was generated in the area extending approximately $500 \mathrm{~m}$ upwind of the LAS. An exception is for a wind direction parallel to the LAS path, when most of the flux is generated within 250-300 m distance from the LAS path. For the dataset considered in this study, this approach resulted in changes in the magnitude of the sensible heat flux ranging from -5 to $7 \%$ in the iterative scenarios. The maximum changes even reached $20 \mathrm{~W} \mathrm{~m}^{-2}$, and changes in more than $20 \%$ of the cases exceeded $10 \mathrm{~W} \mathrm{~m}^{-2}$. When $u_{*}$ based on the eddy covariance was used, the discrepancies ranged from zero to $6 \%$.

The influence of different heat-flux computation scenarios seems to be relatively smaller in comparison with other uncertainties also found in non-urban areas, such as those related to different forms of similarity functions (e.g., Andreas 1988; Hill et al. 1992; De Bruin et al. 
1993; Hartogensis and De Bruin 2005), with uncertainties reaching 10-15\% (e.g., Lagouarde et al. 2006). However, the scenarios of the sensible heat-flux computation considered show that at urban sites with diverse topography, the estimates of sensible heat flux may be enhanced to a certain degree.

In general, the extent of the source area seems to be slightly less sensitive to the heat-flux computation scenarios than the sensible heat flux itself. The footprints retrieved using the PRO and AVE methods bear a strong resemblance. However, the isopleths obtained with the PRO method are more irregular in shape, which is a consequence of the nature of this method. When source areas are estimated for the scenarios with one and three zones for the $z_{H}$ computation, the differences in the size of the source area reach 8-9\%, depending on the scenario. The largest discrepancies are found between footprints obtained using the iterative and EC methods, resulting from the discrepancies in the way $u_{*}$ is obtained from the two methods. It is thus confirmed that when the aerodynamic parameters in the source area of the eddy-covariance and scintillometer methods diverge significantly, the full iterative procedure should be used instead of a simplified algorithm with $u_{*}$ determined independently from the EC method.

Acknowledgements The present work was funded by the Polish National Science Centre under Grant 2011/01/N/ST10/07529 in the years 2011-2014 and by the Polish Ministry of Science and Higher Education under Grant N306 276935 in the years 2008-2011.

Open Access This article is distributed under the terms of the Creative Commons Attribution 4.0 International License (http://creativecommons.org/licenses/by/4.0/), which permits unrestricted use, distribution, and reproduction in any medium, provided you give appropriate credit to the original author(s) and the source, provide a link to the Creative Commons license, and indicate if changes were made.

\section{References}

Andreas EL (1988) Estimating $C_{n}^{2}$ over snow and sea ice from meteorological data. J Opt Soc Am A 5:481-495 Andreas EL (1992) Uncertainty in a path averaged measurement of the friction velocity $u_{*}$. J Appl Meteorol 31:1312-1321

Beyrich F, De Bruin HAR, Meijninger WML, Schipper JW, Lohse H (2002) Results from one-year continuous operation of a large aperture scintillometer over a heterogeneous land surface. Boundary-Layer Meteorol 105:85-97

Beyrich F, Bange J, Hartogensis OK, Raasch S, Braam M, van Dinther D, Gräf D, van Kesteren B, van den Koonenberg AC, Maronga B, Martin S, Moene AF (2012) Towards a validation of scintillometer measurements: the LITFASS-2009 Experiment. Boundary-Layer Meteorol 144:83-112

Christen A, Vogt R (2004) Energy and radiation balance of a central European city. Int J Climatol 24:1395-1421

Clifford S, Ochs G, Lawrence R (1974) Saturation of optical scintillation by strong turbulence. J Opt Soc Am 64:148-154

De Bruin HAR, Kohsiek W, Van den Hurk BJJM (1993) A verification of some methods to determine the fluxes of momentum, sensible heat and water vapour using standard deviation and structure parameter of scalar meteorological quantities. Boundary-Layer Meteorol 63:231-257

De Bruin HAR, Van den Hurk BJJM, Kohsiek W (1995) The scintillation method tested over a dry vineyard area. Boundary-Layer Meteorol 76:25-40

Evans JG, De Bruin HAR (2011) The effective height of a two-wavelength scintillometer system. BoundaryLayer Meteorol 141:165-177. doi:10.1007/s10546-011-9634-0

Evans JG, McNeil DD, Finch JW, Murray T, Harding RJ, Ward HC, Verhoef A (2012) Determination of turbulent heat fluxes using a large aperture scintillometer over undulating mixed agricultural terrain. Agric For Meteorol 166-167:221-233

Ezzachar J, Chehbouni A, Hoedjes JCB, Chehbouni Ah (2007) On the application of scintillometry over heterogeneous grids. J Hydrol 334:493-501

Fortuniak K, Pawlak W, Siedlecki M (2013) Integral turbulence statistics over a central European city centre. Boundary-Layer Meteorol 146:257-276 
Goldbach A, Kuttler W (2013) Quantification of turbulent heat fluxes for adaptation strategies within urban planning. Int I Climatol 33(1):143-159

Göckede M, Markkanen T, Maunder M, Arnold K, Leps J-P, Foken T (2005) Validation of footprint models using natural tracer measurements from a field experiment. Agric For Meteorol 135:314-325

Green AE, McAneney KJ, Astill MS (1994) Surface layer scintillation measurements of daytime heat and momentum fluxes. Boundary-Layer Meteorol 68:357-373

Grimmond CSB, Oke TR (1999) Aerodynamic properties of urban areas derived from analysis of surface form. J Appl Meteorol 38:1262-1292

Gruber MA, Fochesatto GJ, Hartogensis OK, Lysy M (2014) Functional derivatives applied to error propagation of uncertainties in topography to large-aperture scintillometer-derived heat fluxes. Atmos Meas Tech 7:2361-2371

Hartogensis OK, De Bruin HAR (2005) Monin-Obukhov similarity functions of the structure parameter of temperature and TKE dissipation rate in the stable boundary layer. Boundary-Layer Meteorol 116:253276

Hartogensis OK, Watts CJ, Rodriguez J-C, De Bruin HAR (2003) Derivation of an effective height for scintillometers: La Poza experiment in Northwest Mexico. J Hydrometeorol 4:915-928

Hill RJ (1997) Algorithms for obtaining atmospheric surface-layer fluxes from scintillation measurements. J Atmos Ocean Technol 14:456-467

Hill RJ (1988) Comparison of scintillation methods for measuring the inner scale of turbulence. Appl Opt 27(11):2187-2193

Hill RJ, Ochs GR, Wilson JJ (1992) Heat and momentum using optical scintillation. Boundary-Layer Meteorol 58:391-408

Hoedjes JCB, Chehbouni A, Ezzachar J, Escadafal R, De Bruin HAR (2007) Comparison of large aperture scintillometer and eddy covariance measurements: Can thermal infrared data be used to capture footprintinduced differences? J Hydrometeorol 8:144-159

Horst TW, Weil JC (1992) Footprint estimation for scalar flux measurements in the atmospheric surface layer. Boundary-Layer Meteorol 59:279-296

Hsieh CI, Katul G, Chi T (2000) An approximate analytical model for footprint estimation of scalar fluxes in thermally stratified atmospheric flows. Adv Water Resour 23:765-772

Kanda M, Moriwaki R, Roth M, Oke T (2002) Area-averaged sensible heat flux and a new method to determine zero-plane displacement length over an urban surface using scintillometry. Boundary-Layer Meteorol 105:177-193

Kleissl J, Gomez J, Hong S-H, Hendrickx JMH, Rahn T, Defoor WL (2008) Large aperture scintillometer intercomparison study. Boundary-Layer Meteorol 128:133-150

Kotthaus S, Grimmond CSB (2014a) Energy exchange in a dense urban environment-part I: temporal variability of long-term observations in central London. Urban Clim 10:261-280

Kotthaus S, Grimmond CSB (2014b) Energy exchange in a dense urban environment-part II: impact of spatial heterogeneity of the surface. Urban Clim 10:281-307

Lagouarde J-P, Irvine M, Bonnefond J-M, Grimmond CSB, Long N, Oke TR, Salmond JA, Offerle B (2006) Monitoring the sensible heat flux over urban areas using large aperture scintillometery: case study of Marseille city during the ESCOMPTE experiment. Boundary-Layer Meteorol 118:449-476

Meijninger WML (2003) Surface fluxes over natural landscapes using scintillometry. Wageningen University, Wageningen, $164 \mathrm{pp}$

Meijninger WML, Hartogensis OK, Kohsiek W, Hoedjes JCB, Zuurbier RM, De Bruin HAR (2002) Determination of area-averaged sensible heat fluxes with a large aperture scintillometer over a heterogeneous surface-Flevoland field experiment. Boundary-Layer Meteorol 105:37-62

Moene AF, Mejninger WML, Hartogensis OK, Kohsiek W, De Bruin HAR (2005) A review of the relationships describing the signal of a large aperture scintillometer. Wageningen University, Wageningen, $40 \mathrm{pp}$

Pauscher L (2010) Scintillometer measurements above the urban area of London. University of Bayreuth, Bayreuth

Pawlak W, Fortuniak K, Siedlecki M (2011) Carbon dioxide flux in the centre of Łódź, Poland—analysis of a 2-year eddy covariance measurement data set. Int J Climatol 31:232-243

Roth M, Salmond JA, Satyanarayana ANV (2006) Methodological considerations regarding the measurement of turbulent fluxes in the urban roughness sublayer: the role of scintillometery. Boundary-Layer Meteorol 121:351-375

Samain B, Defloor W, Pauwels VRN (2012) Continuous time series of catchment-averaged sensible heat flux from a large aperture scintillometer: efficient estimation of stability conditions and importance of fluxes under stable conditions. J Hydrometeorol 13:423-442

Schmid HP (1994) Source areas for scalar and scalar fluxes. Boundary-Layer Meteorol 67:293-318 
Schmid HP (1997) Experimental design for flux measurements: matching scales of observations and fluxes. Agric For Meteorol 87:179-200

Solignac PA, Brut A, Selves J-L, B'eteille J-P, Gastellu-Etchegorry J-P, Keravec P, B'eziat P, Ceschia E (2009) Uncertainty analysis of computational methods for deriving sensible heat flux values from scintillometer measurements. Atmos Meas Tech 2:741-753

Timmermans WJ, Su Z, Olioso A (2009) Footprint issues in scintillometry over heterogeneous landscapes. Hydrol Earth Syst Sci 13:2179-2190

Ward HC, Evans JG, Grimmond CSB (2014) Multi-scale sensible heat fluxes in the suburban rnvironment from large aperture scintillometry and eddy covariance. Boundary-Layer Meteorol 165:65-89

Ward HC, Evans JG, Grimmond CSB (2015) Infrared and millimetre-wave scintillometry in the suburban environment-Part 2: large-area sensible and latent heat fluxes. Atmos Meas Tech 8:1407-1424

Wood CR, Kouznetsov RD, Gierens RT, Nordbo A, Järvi L, Kallistratova M, Kukkonen J (2013) On the temperature structure parameter and sensible heat flux over Helsinki from sonic anemometry and scintillometry. J Atmos Ocean Technol 30:1604-1615

Wyngaard JC, Izumi Y, Collins SA (1971) Behaviour of refractive-index-structure parameter near the ground. J Opt Soc Am 61:1646-1650

Zhang H, Zhang H (2015) Comparison of turbulent sensible heat flux determined by large-aperture scintillometer and eddy covariance over urban and suburban areas. Boundary-Layer Meteorol 154:119-136. doi:10.1007/s10546-014-9965-8

Zieliński M, Fortuniak K, Pawlak W, Siedlecki M (2013) Turbulent sensible heat flux in Łódź, Central Poland, obtained from scintillometer and eddy covariance measurements. Meteorol Z 22(5):603-613 